\title{
Rates of southeast Greenland ice volume loss from combined ICESat and ASTER observations
}

\author{
Ian M. Howat, ${ }^{1}$ Ben E. Smith, ${ }^{2}$ Ian Joughin, ${ }^{2}$ and Ted A. Scambos ${ }^{3}$ \\ Received 28 April 2008; revised 20 June 2008; accepted 29 July 2008; published 9 September 2008.
}

[1] Repeat satellite laser altimetry is critical for observing the rapidly changing mass balance of the Greenland Ice Sheet. However, sparse sampling and high surface slopes over rapidly thinning, coastal outlet glaciers may result in underestimation of mass loss. Here we supplement ICESatderived surface elevation changes with differenced ASTER digital elevation models of outlet glaciers in southeastern Greenland, the region with the largest concentrated change in outlet glacier mass loss. We estimate a 2002-2005 regional volume-loss rate of $108 \mathrm{~km}^{3} / \mathrm{yr}$. Our results are consistent with drainage-scale GRACE and mass-budget estimates when differences in observation periods are taken into account. The two largest glaciers, Kangerdlugssuaq and Helheim, account for only $28 \%$ of the mass loss, illustrating the combined importance of smaller glaciers and the need for complete observational coverage. Additionally, we find that rapid, concentrated thinning within the outlets represents a small contribution to the total volume change compared to dispersed inland thinning. Citation: Howat, I. M., B. E. Smith, I. Joughin, and T. A. Scambos (2008), Rates of southeast Greenland ice volume loss from combined ICESat and ASTER observations, Geophys. Res. Lett., 35, L17505, doi:10.1029/ 2008 GL034496.

\section{Introduction}

[2] Recent observations indicate that substantial changes in the rate at which the Greenland Ice Sheet discharges mass to the ocean can occur at timescales of years or less [Howat et al., 2007]. This high temporal and spatial variability in discharge presents a challenge for measuring the ice-sheet mass balance, with each of several current methods having their own strengths and weaknesses. The mass-budget method, which observes changes in ice flux from ice velocity and thickness [Rignot and Kanagaratnam, 2006], resolves changes in the mass balance of individual outlet glaciers and is accurate where ice thicknesses are known and surface balance changes are small relative to changes driven by ice dynamics. Satellite coverage often limits the frequency of these estimates, however, potentially aliasing rapid fluctuations. In contrast, satellite gravity measurements from the Gravity Recovery and Climate Experiment (GRACE) [Chen et al., 2006; Luthcke et al., 2006; Velicogna and Wahr, 2005, 2006] provide monthly estimates of mass-change, but at a

\footnotetext{
${ }^{1}$ School of Earth Sciences and Byrd Polar Research Center, Ohio State University, Columbus, Ohio, USA.

${ }^{2}$ Polar Science Center, Applied Physics Laboratory, University of Washington, Seattle, Washington, USA.

${ }^{3}$ National Snow and Ice Data Center, University of Colorado, Boulder, Colorado, USA.
}

Copyright 2008 by the American Geophysical Union. 0094-8276/08/2008GL034496\$05.00 spatial resolution too coarse to resolve specific locations of loss (e.g., at scale of individual outlet glaciers) or to separate glacier mass changes from mass changes in the adjacent ocean. This prevents direct comparison and validation of results with more local, higher-resolution observations. Finally, the Geoscience Laser Altimeter System (GLAS) aboard the Ice, Cloud and Land Elevation Satellite (ICESat) [Thomas et al., 2006] provides relatively accurate, subannually-repeating surface elevation measurements. However, the wide spacing (10's of $\mathrm{km}$ ) between repeat tracks may under-sample the much narrower, rapidly changing outlet glaciers, especially in the south where the fastest thinning has been observed. Consequently, these data have been supplemented with repeat airborne laser altimeter measurements from NASA's Airborne Topographic Mapper (ATM) [Krabill et al., 2004]. These flights, however, only cover a small portion of Greenland's outlets.

[3] Recent studies have successfully measured volume changes of individual Greenland outlet glaciers using repeat Digital Elevation Models (DEMs) from the Advanced Spaceborne Thermal Emission and Reflection radiometer (ASTER) sensor aboard the Terra satellite [Howat et al., 2007; Stearns and Hamilton, 2007]. Since these DEM's are constructed from correlation between brightness patterns in stereo-imagery, high-resolution (15-m) coverage can be obtained for the highly-textured (e.g., crevassed) surfaces at low elevations. While measurement precision of these DEM's is much coarser than laser altimetry $(\sim 10 \mathrm{~m}$ vs. $0.1 \mathrm{~m}$ ), they can clearly resolve the extreme rates of elevation change that occur on many outlet glaciers (10's of $\left.\mathrm{m} \mathrm{yr}^{-1}\right)$. Furthermore, random errors in elevation change are reduced through averaging when summed over large areas to obtain volume-change estimates. Therefore, differenced ASTER DEM's offer a supplemental dataset for constraining surface height changes at low elevations, where ICESat coverage is sparse and rates of change are high. Here, we apply this method to the rapidly thinning southeast portion of the Greenland Ice Sheet. By combining these datasets, we construct a comprehensive map of ice thickness change that we use to assess the spatial distribution of loss. We compare these results with other mass-balance estimates and assess the degree to which ICESat altimetry alone may underestimate loss.

\section{Methods}

\subsection{ASTER DEM Differencing}

[4] ASTER DEM's with a ground resolution of $15 \mathrm{~m}$ were constructed from level-1A imagery using ENVI/IDL. This software builds stereo model geometries from sensor and ephemeris metadata contained within the raw data file and uses cross-correlation to create parallax images from 


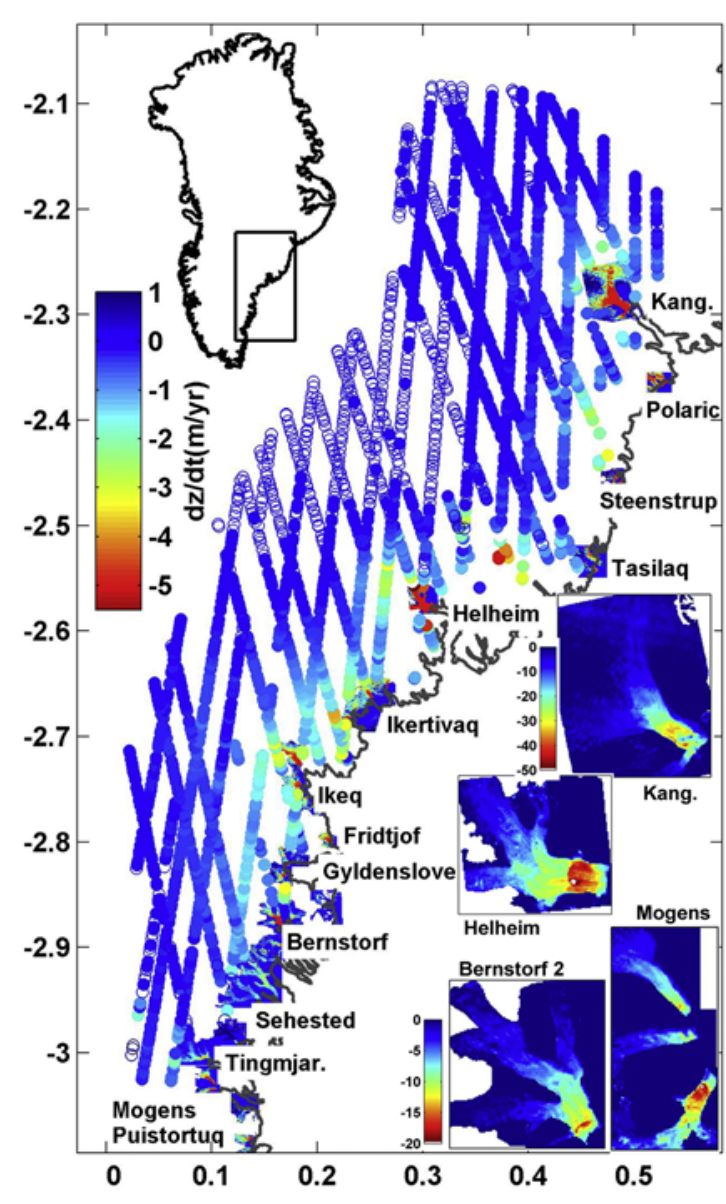

Figure 1. Map of ice surface elevation change $(d z / d t)$ over southeast Greenland from (circles) repeat passes of the Ice, Cloud, and Land Elevation Satellite (ICESat) and (polygons) differencing of Advanced Spaceborne Thermal Emission and Reflection radiometer (ASTER) Digital Elevation Models (DEMs). Open circles denote elevation gain $(d z d t>0)$. Labels denote major outlet glaciers. Map coordinates are in polar stereographic $10^{3} \mathrm{~km}$ east and north. Insets provide magnifications of ASTER-derived thinning rates over the four largest outlets. Kang. and Helheim are on the 0 to $-40 \mathrm{~m} / \mathrm{yr}$ color scale and Bernstorf 2 and Mogens are on the 0 to $20 \mathrm{~m} / \mathrm{yr}$ color scale.

the nadir and backward-looking Band 3 (near-infrared) images [Fujisada et al., 2005]. Each DEM was manually edited to remove spurious elevations. For differencing, we co-registered DEM pairs by minimizing the root-meansquare of the sum of differences over ice-free land using a two-dimensional, least-squares regression. This removed bias, caused by satellite positioning errors and atmospheric variability, from the volume-change estimates by bringing the sum of differences to zero. Random errors in elevationchange are due to errors in horizontal co-registration from satellite positioning $(50 \mathrm{~m})$, which shift surfaces relative to each other and result in increasing error with the degree of slope. For slope magnitudes typical of glacier surfaces $(0.01)$ previous validation studies quote an uncertainty of between $\pm 7 \mathrm{~m}$ to $\pm 10 \mathrm{~m}$ [Fujisada et al., 2005; San and Suzen, 2005]. At the outlet or basin-wide scale of volume-change estimates this error is normally distributed. The standard deviation $(\sigma)$ in elevation change for all off-ice pixels is $10 \mathrm{~m}$ with a mean of zero after vertical co-registration. Conservatively assuming the same standard deviation for on-ice measurements, the $95 \%$ confidence interval for any volume-change measurement is $1.96 \sigma \frac{A}{\sqrt{n}}$ where $A$ is the area of coverage and $n$ is the number of pixels. Assuming errors are uncorrelated at a scale of $200 \mathrm{~m}$ and $\sigma=10 \mathrm{~m}$, this yields an uncertainty in estimated rates of volume-change of less than $10 \%$ for regions with mean thinning rates of greater than $1 \mathrm{~m} / \mathrm{yr}$ and less than $1 \%$ for the entire region covered by ASTER.

[5] Our selection of ASTER imagery provides a compromise between lengthening the repeat period between DEM's to reduce error in rate of change, keeping a consistent temporal baseline between observations for an unambiguous, regional rate calculation, and maximizing coverage. The period from 2002 to 2005 provided the best repeating coverage over most of the region. Use of some 2001 and 2006 imagery, however, was necessary to obtain full coverage (see Table S1 of the auxiliary material). ${ }^{1}$ Where multiple DEM's from a single year overlapped, the mean elevation and acquisition time at that pixel was used for differencing. We note that the time separation between repeat DEM's is not always an integer number of years, which may result in aliasing of seasonal variability in elevation-change rates. However, agreement between volume-change rates presented here for Kangerdlugssuaq, where this offset is the greatest, and mass-budget estimates [Howat et al., 2007] suggests that this effect is small. This is likely because inter-annual dynamic thinning rates within outlet glaciers are large relative to seasonal variability [Krabill et al., 1999, 2004].

\subsection{ICESat/GLAS Repeat Altimetry}

[6] Elevation-change rates for the interior ice sheet were obtained using ICESat GLA12 surface elevation and position altimetry data from the National Snow and Ice Data Center. We determine the mean rate of elevation-change along reference tracks separated by about $30 \mathrm{~km}$ in southeast Greenland with an along-track measurement resolution of $170 \mathrm{~m}$. Each reference track was repeated to within $\pm 250 \mathrm{~m}$ eleven times between September 2003 and March 2007. Although the formal regression technique described here is new, similar techniques have been used to measure surface slopes in Greenland [Yi et al., 2005], to identify ice shelf grounding zones [Fricker and Padman, 2006], and to identify subglacial lakes [Fricker et al., 2007]. Using repeat tracks rather than crossovers [Smith et al., 2005] to measure elevation changes greatly increases measurement density and consequently should result in less spatial aliasing of elevation-change signals. A detailed description of the repeat-track procedure and a formal error analysis is presented in the auxiliary material. We estimate the typical uncertainty in ICESat-derived elevation changes to be approximately $0.1 \mathrm{~m} \mathrm{yr}^{-1}$, resulting in errors in volumechange rate estimates of less than $12 \%$ for the sub-regions discussed in Section 4 (depending on surface slope) and less than $7 \%$ for the entire study region.

\subsection{Gridded Elevation- and Volume-Change Rate Estimates}

[7] To combine the ASTER- and ICESat-derived maps of elevation-change rates, we resampled each gridded dataset

\footnotetext{
${ }^{1}$ Auxiliary materials are available in the HTML. doi:10.1029/ 2008 GL034496.
} 
Table 1. Mean Thinning Rates $(\overline{d z / d t})$, Ice Sheet Area, and Rates of Volume Change $(d V / d t)$ for the Drainages Delineated in Figure 2

\begin{tabular}{|c|c|c|c|c|c|c|c|c|c|}
\hline & \multicolumn{3}{|c|}{$\overline{d z / d t}\left(\mathrm{myr}^{-1}\right)$} & \multicolumn{3}{|c|}{ Area $^{\mathrm{a}}\left(\mathrm{km}^{2}\right)$} & \multicolumn{3}{|c|}{$d V / d t\left(\mathrm{~km}^{3} \mathrm{yr}^{-1}\right)$} \\
\hline & Total & $>2000 \mathrm{~m}^{\mathrm{b}}$ & $<2000 \mathrm{~m}^{\mathrm{c}}$ & Total & $>2000 \mathrm{~m}^{\mathrm{b}}$ & $<2000 \mathrm{~m}^{\mathrm{c}}$ & Total & $>2000 \mathrm{~m}^{\mathrm{b}}$ & $<2000 \mathrm{~m}^{\mathrm{c}}$ \\
\hline Kangerd. & -0.33 & -0.14 & -2.03 & 49,000 & $90 \%$ & $10 \%$ & -16.1 & -6.1 & -10.0 \\
\hline North & -1.04 & -0.49 & -1.51 & 28,000 & $46 \%$ & $54 \%$ & -28.8 & -6.2 & -22.6 \\
\hline Helheim & -0.26 & -0.01 & -1.84 & 54,000 & $86 \%$ & $14 \%$ & -13.8 & -0.4 & -13.5 \\
\hline Mid & -0.70 & -0.26 & -1.23 & 41,000 & $55 \%$ & $45 \%$ & -28.9 & -6.0 & -22.9 \\
\hline South & -0.49 & -0.33 & -0.78 & 42,000 & $65 \%$ & $35 \%$ & -20.6 & -9.2 & -11.4 \\
\hline Total & -0.50 & -0.18 & -1.33 & 214,000 & $72 \%$ & $28 \%$ & -108.2 & -27.7 & -80.4 \\
\hline
\end{tabular}

${ }^{\mathrm{a}}$ Excluding water and exposed rock.

${ }^{b}$ Values for areas above 2000 m elevation.

${ }^{\mathrm{c}}$ Values for areas below $2000 \mathrm{~m}$ elevation.

onto a single $200-\mathrm{m}$ grid, providing enough resolution to capture elevation-change rates over individual outlet glaciers (Figure 1). The sparsity of ICESat measurements within the outlets dictates that where ASTER data are present, they entirely determine the gridded elevationchange rate. After merging the gridded datasets we linearly interpolated over gaps between ICESat and ASTER grid values. For volume-change calculations we apply a fractional ice cover mask, constructed from high-resolution RADARSAT and ASTER imagery, to adjust measurements at the ice margins. We do not attempt to apply a correction for isostatic uplift because, assuming typically-cited values on the order of $0 \pm 1 \mathrm{mmyr}^{-1}$ [Thomas et al., 2006; Zwally et al., 2005], this contribution is no more than $2 \%$ of the total volume-change rate.

\section{Results}

\subsection{Elevation- and Volume-Change Rates and Distribution}

[8] Our measurements show that elevation changed at an average rate of $-0.5 \mathrm{~m} \mathrm{yr}^{-1}$, giving a combined volume-change rate of $-108.2 \mathrm{~km}^{3} \mathrm{yr}^{-1}$ (Table 1 and Figure 2) over the combined ICESat/ASTER mapped surface area of $214,000 \mathrm{~km}^{2}$. Rates of elevation loss reach over $40 \mathrm{~m} \mathrm{yr}^{-1}$ within the marine-terminating outlet glaciers, with nearly every glacier showing rapid thinning. Elevation loss in the range of 0.5 to $1.5 \mathrm{~m} \mathrm{yr}^{-1}$ is widespread along the margin. Most of the area of elevation gain is in the upper Helhiem drainage region, with values as high as $30 \mathrm{~cm} \mathrm{yr}^{-1}$ (Figure 2). Smaller regions of elevation gain are found in the South and Kangerdugssuaq drainages.

[9] Regions below 2000-m elevation comprise $28 \%$ of the total ice area, but accounted for $74 \%$ of the volume change because they had over 7-times the rate of elevation loss than those above $2000 \mathrm{~m}$. Helheim and Kangerdlugssuaq are much larger contributors to this loss than any other individual glaciers. The combined contribution of the smaller glaciers, however, dominates the signal, representing over $72 \%$ of the total rate of loss.

[10] Converting the estimated rate of volume change to mass change requires an estimate of the density of the volume change. The lower bound for this estimate applies if the volume change is due only to changes in surface accumulation rate so that the corresponding mass change would then be equal to the volume change multiplied by the density of the snow. The upper bound applies if the volume change is due only to changes in the ice ablation rate or ice dynamics so that the density of ice would apply. In reality, the short-term sensitivity of averaged surface elevation change to variations in accumulation and ablation should fall between these two limits due to firn ablation and densification during the averaging period, the rate of the later being sensitive to variations in both accumulation and temperature [Wingham, 2000]. The uncertainty in these variables, as well as the high uncertainty of empirical firn-

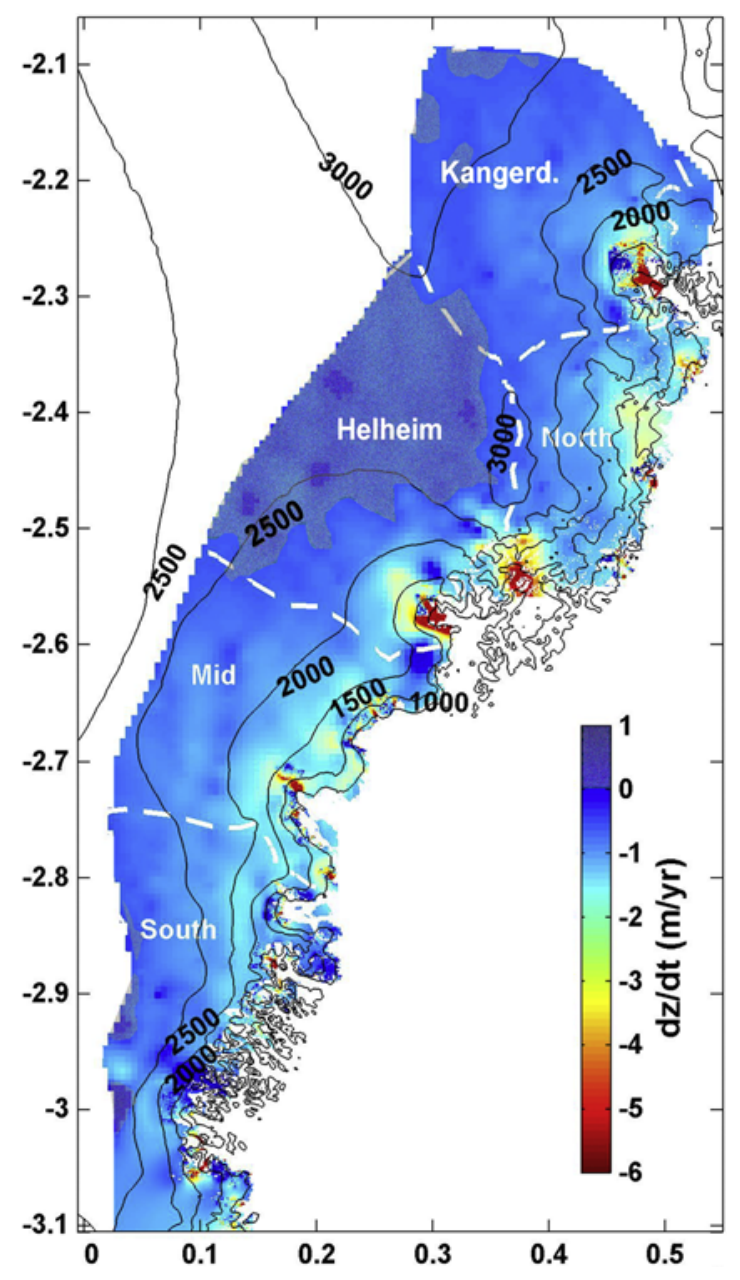

Figure 2. Map of $d z / d t$ from the combined ICESat and ASTER datasets. Texture highlights areas where $d z / d t>0$. Contours are surface elevation from a 1-km resolution DEM [Bamber et al., 2003] and are at $500 \mathrm{~m}$ intervals. White hatches delineate drainage zones in Table 1. The map projection is the same as in Figure 1. 
compaction models, prevents a reliable estimate of the density factor for converting ice volume to mass. Instead, we compare our volume-change estimates to mass-loss estimates from other, independent sources to assess their agreement under the assumption that the observed volume change is due primarily to ice dynamics, as suggested by recent studies [Krabill et al., 1999, 2004; Rignot and Kanagaratnam, 2006].

\subsection{Comparison With Regional GRACE Estimates}

[11] Our results compare closely with mass-loss estimates obtained from GRACE gravity measurements over a similar time period [Luthcke et al., 2006]. Assuming a mean ice density of $900 \mathrm{~kg} \mathrm{~m}^{-3}$, they obtain an ice volume-equivalent change of $-78 \pm 15 \mathrm{~km}^{3} \mathrm{yr}^{1}$ between summer 2003 and summer 2005 over the area corresponding to the South, Mid and Helheim catchments, where we observe a rate of $-63 \mathrm{~km}^{3} \mathrm{yr}^{-1}$. The shorter GRACE estimate is more sensitive to Helheim glacier's $7.7 \mathrm{~km}^{3} \mathrm{yr}^{-1}$ additional increase in ice discharge between 2004 and 2005 [Howat et al., 2007]. Consequently, our longer time interval would yield a lower rate of change than the GRACE time interval that bracketed the period of increasing discharge. Another difference between our estimates and the gravity anomaly estimates is found in the elevation partitioning of the volume change. GRACE estimates that elevations over $2000 \mathrm{~m}$ contributed to over $50 \%$ of the total rate of volume loss while we estimate only a $25 \%$ contribution. Our contribution increases to $50 \%$, however, if elevations down to $1600 \mathrm{~m}$ are included, representing a mean horizontal shift of only about $20 \mathrm{~km}$. This difference is most easily attributed to the coarse spatial resolution $(>100 \mathrm{~km})$ of the GRACE estimates.

\subsection{Comparison With Mass-Budget Estimates}

[12] The rapid changes in discharge make differences in observational period important in comparisons between our results and mass-budget estimates [Rignot and Kanagaratnam, 2006]. Using the same drainage areas as that study (Figure 2), our estimate of $-13.8 \mathrm{~km}^{3} \mathrm{yr}^{-1}$ mass loss for Helheim glacier is close to the mass-budget estimate of $-12.0 \mathrm{~km}^{3} \mathrm{yr}^{-1}$ in 2005 . In this case, Helheim's relatively gradual increase in discharge [Howat et al., 2005, 2007] results in similar loss estimates despite differences in observation periods. In contrast, our estimated loss rate of $-49.4 \mathrm{~km}^{3} \mathrm{yr}^{-1}$ for the Mid and South regions is substantially less than the 2005 mass-budget estimate of -69.4 $\mathrm{km}^{3} \mathrm{yr}^{-1}$, but close to the 2000 estimate of $-49.2 \mathrm{~km}^{3} \mathrm{yr}^{-1}$. This is consistent with a widespread increase in outlet glacier discharge between 2003 and 2005 [Howat et al., 2008]. Lastly, the doubling of Kangerdlugssuaq's discharge between 2004 and 2005 [Howat et al., 2007; Luckman et al., 2006], close to the end of our ASTER observations, may explain why our estimate of $-16.1 \mathrm{~km}^{3} \mathrm{yr}^{-1}$ is approximately halfway between the 2000 and 2005 massbudget estimates.

\section{Discussion}

[13] The high-resolution picture of ice thinning presented by this dataset helps to resolve the sources and distribution of change over the region. By assuming that the elevation changes we observe represent changes in the volume of ice, we estimate rates of loss that are consistent with estimates from other, independent methods. The agreement between these estimates and discharge estimates helps to confirm that most of observed mass loss in southeast Greenland is due to changes in ice dynamics, rather than surface mass balance.

[14] These data also confirm that the mass-loss contribution of the two largest glaciers, Helheim and Kangerdlugssuaq, is only about one-quarter of the total volume-change rate for the region. Instead, the dominant source of mass loss is the combined change of the numerous, smaller marineterminating outlet glaciers along the coast. This corroborates mass-budget results [Rignot and Kanagaratnam, 2006] and is consistent with the widespread, near-synchronous retreat and acceleration of most of the tidewater glaciers along this coast between 2003 and 2005 [Howat et al., 2008]. This behavior suggests a pan-regional climate or ocean-related forcing. Furthermore, this distribution of change underscores the need of complete spatial coverage of observations of mass loss. For example, the relatively small North region has a very large contribution to the total rate of loss $(27 \%)$ but was not included in past mass-budget analyses [Rignot and Kanagaratnam, 2006]. Such high rates of thinning must be due to ice dynamics and, as with the other regions in the study area, are likely linked to outlet glacier acceleration.

[15] Our results reveal a relatively small contribution of rapidly thinning regions within outlet glacier trunks to the total rate of volume loss. While thinning rates within the trunks exceed 10's of $\mathrm{m} \mathrm{yr}^{-1}$, much of the loss is from slower, inland thinning over tens of thousands of $\mathrm{km}^{2}$. Similar results apply to Pine Island Glacier in Antarctica [Joughin et al., 2003; Payne et al., 2004]. Alone, ASTER captures only $28 \%$ of the combined ASTER/ICESat volume change for the area below $2000 \mathrm{~m}$, and $21 \%$ for the entire study area. This large contribution of inland ice to volume loss in the southern portion of the study area is consistent with its sustained negative mass balance since the mid1990's [Krabill et al., 1999; Rignot et al., 2004].

[16] Our data provides insight into the patterns and rates of inland diffusion of thinning out of the confined outlets. Profiles of thinning rate and elevation for the major outlets of each region are shown in Figure S1. Thinning rates decrease sharply from their maximum near the front to a point 25 to $30 \mathrm{~km}$ inland. Further inland of this point, the thinning rate decreases more gradually, reaching near zero within approximately $100 \mathrm{~km}$ of the front. On each profile, the breakpoint between these slopes corresponds to an increase in surface slope toward the margin. Since kinematic propagation of dynamic thinning and acceleration scales non-linearly with surface slope [Weertman, 1958], we would expect that thinning resulting from stretching near the front would travel more quickly over these steeper regions. For the northern half of the study area, where glacier acceleration occurred recently, this indicates that dynamic thinning propagated rapidly out of the outlet region, spanning several 10's of $\mathrm{km}$ in a few years or less. Radial diffusion above the outlet constriction would cause an abrupt decrease in thinning rate. These factors may explain, in part, why rates of volume loss estimated from inland extrapolation of near-front thinning rates [Stearns and Hamilton, 2007] are several times larger than mass-budget [Howat et al., 2007; 
Rignot and Kanagaratnam, 2006] and regional GRACE estimates [Luthcke et al., 2006], as well as the estimates presented here.

\section{Conclusions}

[17] Our results reveal that rapid ice thinning in southeast Greenland, associated with accelerated ice flow, is not localized in confined outlet glaciers but is distributed well inland of the glaciers' main trunks. The large contribution to the total mass loss of glaciers in southern portion of the study corroborates long-term mass loss there [Krabill et al., 1999; Rignot et al., 2004]. Since most of the glacier acceleration in the northern half of the study area occurred in just the past several years, this indicates that drawdown within the outlets migrated rapidly to the interior, spanning 10 's of $\mathrm{km}$ over that time. Continued changes in outlet glacier flow could therefore quickly impact ice sheet dynamics and mass balance. High-resolution observations of mass-loss, such as those presented here, will be crucial for resolving where change is occurring, allowing for targeted studies of processes.

[18] Acknowledgments. NASA grants NNG06GE5SG and NNG06GE50G supported the contribution of I. Howat and T. Scambos. NASA grant NNX07AK45G supported B. Smith's and I. Joughin's contribution.

\section{References}

Bamber, J. L., et al. (2003), A new bedrock and surface elevation data set for modelling the Greenland Ice Sheet, Ann. Glaciol., 37, 351-356.

Chen, J. L., et al. (2006), Satellite gravity measurements confirm accelerated melting of Greenland ice sheet, Science, 313(5795), 1958-1960.

Fricker, H. A., and L. Padman (2006), Ice shelf grounding zone structure from ICESat laser altimetry, Geophys. Res. Lett., 33, L15502, doi:10.1029/2006GL026907.

Fricker, H. A., et al. (2007), An active subglacial water system in West Antarctica mapped from space, Science, 315(5818), 1544-1548, doi:10.1126/science.1136897.

Fujisada, H., et al. (2005), ASTER DEM performance, IEEE Trans. Geosci. Remote Sens., 43(12), 2707-2714.

Howat, I. M., I. Joughin, S. Tulaczyk, and S. Gogineni (2005), Rapid retreat and acceleration of Helheim Glacier, east Greenland, Geophys. Res. Lett., 32, L22502, doi:10.1029/2005GL024737.

Howat, I. M., et al. (2007), Rapid changes in ice discharge from Greenland outlet glaciers, Science, 315(5818), 1559-1561, doi:10.1126/ science. 1138478 .

Howat, I. M., et al. (2008), Synchronous retreat and acceleration of southeast Greenland outlet glaciers 2000-2006: Ice dynamics and coupling to climate, J. Glaciol., in press.

Joughin, I., E. Rignot, C. E. Rosanova, B. K. Lucchitta, and J. Bohlander (2003), Timing of recent accelerations of Pine Island Glacier, Antarctica, Geophys. Res. Lett., 30(13), 1706, doi:10.1029/2003GL017609.
Krabill, W., et al. (1999), Rapid thinning of parts of the southern Greenland ice sheet, Science, 283(5407), 1522-1524.

Krabill, W., et al. (2004), Greenland Ice Sheet: Increased coastal thinning, Geophys. Res. Lett., 31, L24402, doi:10.1029/2004GL021533.

Luckman, A., T. Murray, R. de Lange, and E. Hanna (2006), Rapid and synchronous ice-dynamic changes in east Greenland, Geophys. Res. Lett., 33, L03503, doi:10.1029/2005GL025428.

Luthcke, S. B., et al. (2006), Recent Greenland ice mass loss by drainage system from satellite gravity observations, Science, 314(5803), $1286-1289$.

Payne, A. J., A. Vieli, A. P. Shepherd, D. J. Wingham, and E. Rignot (2004), Recent dramatic thinning of largest West Antarctic ice stream triggered by oceans, Geophys. Res. Lett., 31, L23401, doi:10.1029/ 2004GL021284.

Rignot, E., D. Braaten, S. P. Gogineni, W. B. Krabill, and J. R. McConnell (2004), Rapid ice discharge from southeast Greenland glaciers, Geophys. Res. Lett., 31, L10401, doi:10.1029/2004GL019474.

Rignot, E., and P. Kanagaratnam (2006), Changes in the velocity structure of the Greenland Ice Sheet, Science, 311(5763), 986-990, doi:10.1126/ science. 1121381 .

San, B. T., and M. L. Suzen (2005), Digital elevation model (DEM) generation and accuracy assessment from ASTER stereo data, Int. J. Remote Sens., 26(22), 5013-5027.

Smith, B. E., C. R. Bentley, and C. F. Raymond (2005), Recent elevation changes on the ice streams and ridges of the Ross Embayment from ICESat crossovers, Geophys. Res. Lett., 32, L21S09, doi:10.1029/ 2005GL024365.

Stearns, L. A., and G. S. Hamilton (2007), Rapid volume loss from two east Greenland outlet glaciers quantified using repeat stereo satellite imagery, Geophys. Res. Lett., 34, L05503, doi:10.1029/2006GL028982.

Thomas, R., E. Frederick, W. Krabill, S. Manizade, and C. Martin (2006), Progressive increase in ice loss from Greenland, Geophys. Res. Lett., 33, L10503, doi:10.1029/2006GL026075.

Velicogna, I., and J. Wahr (2005), Greenland mass balance from GRACE, Geophys. Res. Lett., 32, L18505, doi:10.1029/2005GL023955.

Velicogna, I., and J. Wahr (2006), Acceleration of Greenland ice mass loss in spring 2004, Nature, 443(7109), 329-331.

Weertman, J. (1958), Travelling waves on glaciers, Int. Assoc. Hydrol. Sci. Publ., 47, 162-168.

Wingham, D. J. (2000), Small fluctuations in the density of the and thickness of a dry firn column, J. Glaciol., 46(154), 399-411.

Yi, D. H., et al. (2005), ICESat measurement of Greenland ice sheet surface slope and roughness, Ann. Glaciol., 42, 83-89.

Zwally, H. J., et al. (2005), Mass changes of the Greenland and Antarctic ice sheets and shelves and contributions to sea-level rise: 1992-2002, J. Glaciol., 51(175), 509-527.

I. M. Howat, School of Earth Sciences, Ohio State University, 1090 Carmack Road, Columbus, OH 43210-1002, USA. (ihowat@gmail.com)

I. Joughin and B. E. Smith, Polar Science Center, Applied Physics Laboratory, University of Washington, 1013 NE 40th Street, Seattle, WA 98105-6698, USA.

T. A. Scambos, National Snow and Ice Data Center, University of Colorado, 1540 30th Street, Boulder, CO 80309-0449, USA 